\title{
PEPERITAS EN COSTA RICA
}

\author{
COSTA RICAN PEPERITES
}

\section{Daniel Soto ${ }^{1 *} \&$ Guillermo E. Alvarado 2,3}

\section{${ }^{1}$ Ministerio de Obras Públicas y Transportes, División Obras Públicas, Dirección Ingeniería, Departamento de Geología, Apdo. 10176-1000, San José, Costa Rica ${ }^{2}$ Instituto Costarricense de Electricidad, Apdo. 10032-1000, San José, Costa Rica ${ }^{3}$ Centro de Investigaciones Geológicas Universidad de Costa Rica, San José, Costa Rica \\ *Autor para contacto: danielsotoa@gmail.com}

(Recibido: 22/03/2012 ; aceptado: 17/12/2012)

\begin{abstract}
This paper describes petrographically and genetically, a number of peperites, as examples of spatial and temporal coexistence of magmatism and sedimentation in Costa Rica. The cases are presented in basic igneous complexes (ophiolites), mixtures varying from incomplete (megablocks of radiolarite with diabase in the Nicoya Complex) to complete mixes in various stages of Maastrichtian-Paleocene (Golfito Formation) or Paleocene pelagic limestones with basalts (Quepos Subcomplex or Tulín Formation) to form brechoid and pillowed peperites. Within the Oligo-Miocene arc, there are examples extended along the Talamanca range and its foothills, as well as Sarapiquí's plains represented for brechoid and bulbous (fluidal) peperites in latiandesitic lavas (Pacacua Formation) or brechoid peperitic pipes in ignimbrites (Mata de Limón Member) or possible brechoid peperites in lavas in the Crucitas mining prospect (Cureña Formation), or simple brechoid peperites in andesitic flow (Pacacua Formation, in Talamanca) or as hydroclastic breccias with fragments of dacitic composition in lava flow deposits of Carbonal Guanacaste, just between the beaches Cabuyal and Naranjo. All these rocks represented proximal equivalents of the explosive, effusive and subvolcanic volcanism (endogenous domes and criptodomes) and his concomitance with the fluvial sedimentation. In Quaternary period, we have a sample in the base of Tiribí Formation in contact with Palmares Lacustrine. Also this paper included possible and potential cases. It hopes that the description and interpretation of this type of rocks helps to its identification in other regions of Costa Rica and Central America in general, as well as a potential source for the exploration of valuable metals.
\end{abstract}

Keywords: Peperites, hydroclastic breccias, criptodomes, volcanism and sedimentation, Costa Rica

RESUMEN: El presente trabajo describe petrográfica y genéticamente, una serie de hallazgos de peperitas como ejemplos de coexistencia espacial y temporal del magmatismo con la sedimentación en Costa Rica. Los casos se presentan en complejos ígneos básicos (ofiolitas) variando desde mezclas incompletas (megabloques de radiolaritas con diabasas en el Complejo de Nicoya) hasta mezclas completas en varios grados de calizas pelágicas del Maastrictiano-Paleoceno 
(Formación Golfito) o del Paleoceno con basaltos (Subcomplejo Quepos o Formación Tulín) para dar peperitas brechoides y bulbosas. Dentro del arco Oligo-Mioceno, se tienen ejemplos a lo largo de la cordillera de Talamanca y sus estribaciones, así como en las llanuras de Sarapiquí, representados por peperitas brechoides, fluidales y bulbosas en cuerpos de lava latiandesíticos (Formación Pacacua) o chimeneas peperíticas brechoides en ignimbritas (Miembro Mata de Limón), o posibles peperitas brechoides en los depósitos de flujos de lava del prospecto minero de Crucitas (Formación Cureña), o simples posibles peperitas brechoides en flujos de lava andesíticas (Formación Pacacua en Talamanca), o como brechas hidroclásticas con fragmentos de composición dacítica de Carbonal en Guanacaste, justamente entre las playas Cabuyal y Naranjo. Todas ellas serían los equivalentes proximales del vulcanismo explosivo, efusivo y subvolcánico (domos endógenos y criptodomos) y su concomitancia con la sedimentación fluvial. En el Cuaternario, un ejemplo se da en la base de la Formación Tiribí al contacto con el lacustre de Palmares. Se incluyen en el presente trabajo, además, casos posibles o potenciales. Se espera que la descripción e interpretación de este tipo de rocas ayude a su identificación en otras regiones de Costa Rica y Centroamérica en general, así como una fuente potencial para la prospección de metales valiosos.

Palabras clave: Peperitas, brechas hidroclásticas, criptodomos, vulcanismo y sedimentación, Costa Rica.

\section{INTRODUCCIÓN}

La interrelación espacio-temporal del magmatismo (intrusiones y vulcanismo) con la sedimentación son casos muy tratados desde los primeros trabajos de geología, tanto a nivel mundial como a nivel local en Costa Rica. Así, en los esquemas paleogeográficos suelen presentarse como un hecho común la presencia de volcanes activos que evolucionaron con la intrusión de un magma que asciende sobre cuencas marinas hasta emerger y verter sus productos en la superficie $y$, de esta manera, coexistir con la sedimentación y ayudar a su colmatación. Sin embargo, las evidencias en el campo, de intrusiones o vulcanismo contemporáneo y asociado con la sedimentación de modo directo, prácticamente nunca se han mostrado, no por el hecho de no existir, sino porque suelen no reconocerse por desconocimiento o por interpretarse de otro modo.

Las peperitas, en términos generales, son una brecha volcano-sedimentaria producto de la intrusión subvolcánica en sedimentos inconsolidados o la mezcla de coladas de lava o depósitos de flujos piroclásticos con sedimentos normalmente saturados en agua, siendo una prueba de la coexistencia espacio-temporal del magmatismo (sea de textura plutónica hipoabisal o bien volcánica, o como una intrusión piroclástica) con la sedimentación (White et al., 2000, y referencias allí citadas). No solo nos dice que la intrusión posee una edad similar o cercana a la de los sedimentos y, por lo tanto, su relativo sincronismo y el estado plástico de los mismos, sino que pueden ser sectores interesantes para las mineralizaciones de metales preciosos dada su permeabilidad primaria relativamente elevada y por ser conductos ígneos en contacto con sedimentos húmedos.

Umaña \& Afonso (1969) quizás fueron de los primeros en identificar cómo materiales lacustrinos subían plásticamente por las fracturas de la colada de Cervantes. Schmidt-Effing (1979, 1980), por su parte, fue quizás el primero que interpreta que algunos sedimentos radiolaríticos o calcáreos presentes en complejos ígneos básicos u ofiolíticos de Costa Rica (Complejo de Nicoya, Subcomplejo Quepos, Formación Golfito) podrían ser mezclas o megabrechas volcano-sedimentarias. Sin embargo, sus observaciones no fueron en ese momento aceptadas por los investigadores y fueron puestas al nivel de tan solo como una mera cita, prácticamente anecdótica. Dos décadas después, observaciones geológicas similares volverían a ser tomadas en cuenta como una base para re-interpretar las asociaciones magmático-sedimentarias de los complejos ofiolíticos a la luz de modernas técnicas isotópicas y trabajo de campo adicionales.

Alvarado (1984) menciona la posibilidad de que parte de las lavas mapeadas por Rivier (1979) sean contemporáneas con la sedimentación de Pacacua, hecho que tampoco fue tomado 
en consideración en investigaciones posteriores. Pasaría una década, cuando De la Cruz (1994) describe y al parecer menciona por primera vez el término peperita para Costa Rica, a raíz de una serie de núcleos realizados para la evolución vulcanológica del prospecto minero de Crucitas, pero adolece del hecho de que siempre se cuenta con la limitante de que las perforaciones no dan una buena perspectiva de la tercera dimensión o de las inter-relaciones.

Ya en el presente siglo, Alvarado \& Gamboa (2008), Quintanilla et al. (2008) y Alvarado et al. (2009b) mencionan la existencia de peperitas, pero sus descripciones son escuetas, dado que los objetivos de dichos trabajos eran otros.

La presente investigación expone y describe con más detalle una serie de casos de peperitas que varían desde aquellos bien identificados en Costa Rica (Fig. 1) hasta otros que por la escala o tipo de afloramiento, o por ser descripciones a partir de perforaciones, no lo son, pero presentan características suficientes para hacerles potencialmente acreedores de dicho calificativo. Como fin último, pero quizás el más importante, es que se espera que el presente trabajo sea una base para que otros geólogos puedan reconocer en su trabajo de campo, casos similares no solo en nuestro país, sino en el resto de los países vecinos centroamericanos.

\section{TERMINOLOGÍA}

El término peperita (pépérite) nace a inicios del siglo XIX. La mayoría de autores están de acuerdo en que las primeras descripciones detalladas de rocas que dieron origen al término son del inglés G.P. Scrope en los años de 1827, 1858 y 1862, aunque fue P.L. Cordier en 1816 quien la describe para Francia en Limagne d'Auvergne de la región central, como una toba clara, de aspecto brechoso, siendo está la localidad tipo de esta clase de roca. Scrope le da el nombre de calcareous peperino a un conglomerado volcánico compuesto de fragmentos de basalto y escoria (sin pómez o sin material traquítico), unidos ya sea por adhesión o simplemente por cemento calcáreo o arcilloso, originalmente blando de origen lacustrino que fue perturbado por la intrusión. Su nombre peperino, después cambiado a peperita, proviene del hecho que esta mezcla se parece a los granos de pimienta y sal (Goër de Herve, 2000).

White et al. (2000) redefine el término peperita como la roca formada generalmente in situ por la desintegración de una intrusión magmática y mezcla con sedimento inconsolidado o poco consolidado y generalmente húmedo. Así, el término peperita se refiere también a mezclas generadas por el mismo proceso que opera en los contactos de lavas y depósitos volcaniclásticos calientes con sedimentos. Claramente, existen otras acepciones o modo de ver las peperitas (ver Goër de Herve, 2000), pero para nuestros fines, utilizaremos el trabajo de White et al. (2000).

En la formación de peperitas se genera una desintegración o fragmentación del magma para formar clastos juveniles y una mezcla de estos clastos en un sedimento huésped, con una gran variedad de tamaño de grano, composición, cohesión, porosidad y permeabilidad, ha sido descrito como huésped de la peperita (Skilling et al., 2002).

\section{Tipos de peperitas}

Busby-Spera \& White (1987) distinguen dos tipos texturales de peperitas con respecto a la forma de los clastos juveniles que predominan (Fig. 1). Una de ellas son las peperitas blocosas en donde los clastos juveniles van a presentar formas angulares, poliédricas, blocosas a irregulares. Squire \& McPhie (2002) las describen como grupos de clastos blocosos que pueden presentar texturas en rompecabezas (jigsaw) y clastos rotados. El otro tipo son las denominadas peperitas globulares también llamadas como fluidales en donde los clastos presentan formas similares a los flujos de lava en almohadillas envueltos por el sedimento huésped y viceversa (Busby-Spera \& White, 1987). En la literatura también han sido descritas peperitas resultantes de la mezcla de estos dos tipos o transicionales.

Las evidencias de campo para el reconocimiento de peperitas son: a) contactos discordantes y anómalos o extraños (geometría irregular) entre la intrusión magmática con los sedimentos huésped, 


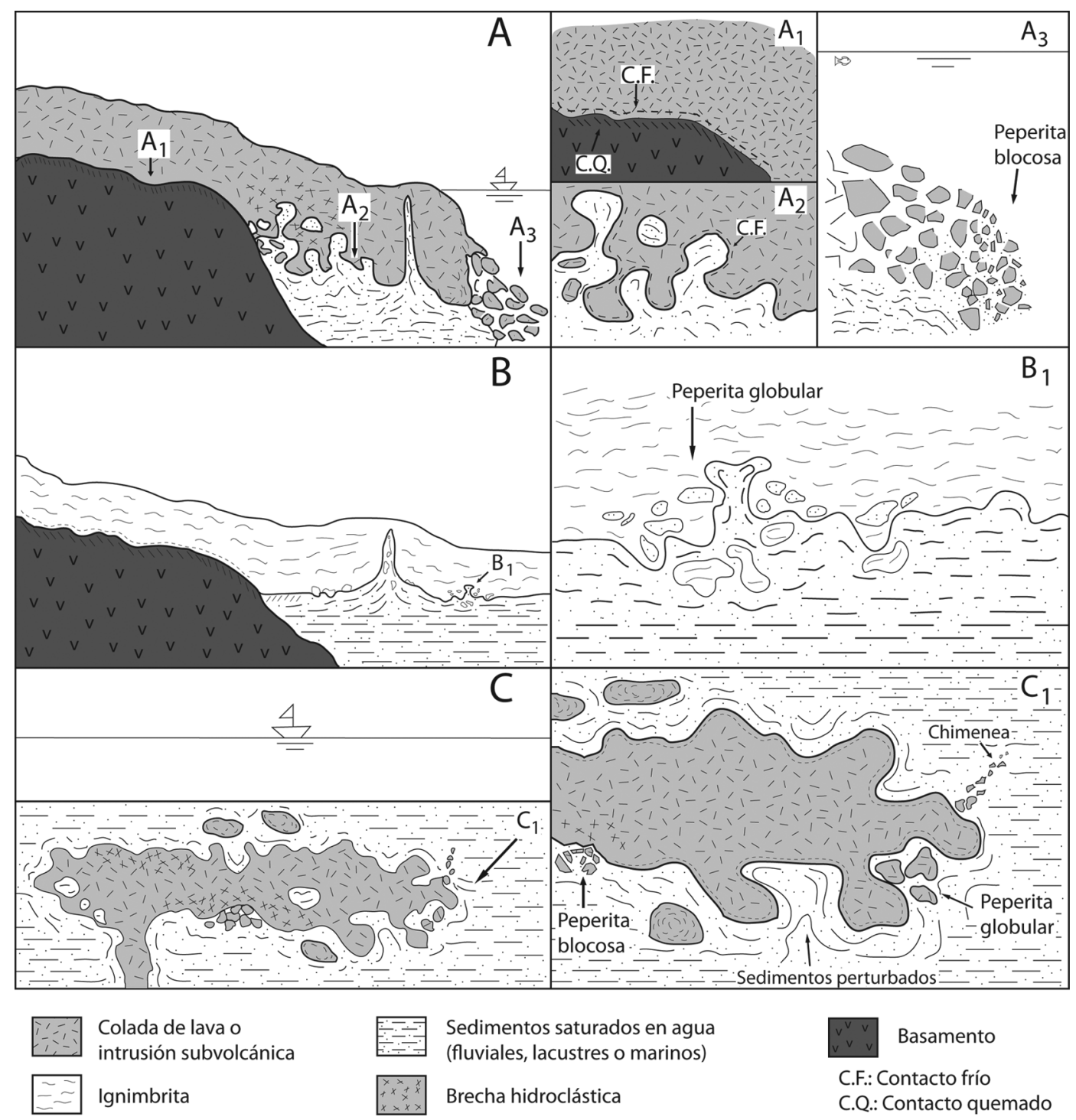

Fig. 1: Tipos de peperitas según textura de los clastos juveniles (ver explicación en el texto así como referencias complementarias).

b) destrucción de estructuras sedimentarias de los componentes sedimentarios adyacentes debido a la intrusión ígnea, perdiendo normalmente -pero no siempre- parte de su estratificación y gradación, c) sedimentos vesiculados debido a la descompresión de la intrusión, así como presencia de sedimentos rellenando vesículas o fracturas en la intrusión (Skilling et al., 2002), d) el componente ígneo, presenta enfriamiento parcial o total (contacto frio) en contacto con el sedimento (White et al. 2000). 


\section{CASOS POSIBLES Y COMPROBADOS DE PEPERITAS EN COSTA RICA}

A continuación enumeraremos una serie de casos de estudio, descritos desde las litologías más antiguas a las más jóvenes. Se subdividen en casos comprobados y casos probables o posibles, ya sea o que requieran de mas investigación, o que el afloramiento desapareció por cobertura vegetal o la construcción de obras de infraestructura, o por que se trate de perforaciones no disponibles y cuya interpretación espacial resulta más complicada (Fig. 2).

\section{Casos comprobados de peperitas}

\section{Península de Nicoya (Jurásico-Cretácico)}

La existencia e interpretación de rocas sedimentarias pelágicas, principalmente radiolaritas con rocas ígneas (intrusivas y extrusivas) ha sido motivo de estudio por décadas en la península de Nicoya en correspondencia con la unidad llamada Complejo de Nicoya. Schmidt-Effing $(1979,1980)$ fue quizás uno de los primeros en proponer que algunos sedimentos radiolaríticos presentes en el Complejo de Nicoya corresponderían con inclusiones sedimentarias (xenolitos o "mélange" volcánico).

La anterior interpretación no fue tomada en consideración o como relevante por los subsiguientes investigadores, quienes optaron por una gran diversidad de modelos, prevaleciendo estos sobre las evidencias de campo, en gran parte bajo la conceptualización válida, pero no única, de que las radiolaritas se deben de depositar sobre un basamento ígneo básico. Aunque lo anterior es cierto, impidió que se visualizaran las evidencias de campo que indicaban que las radiolaritas, en su mayor parte, estaban claramente intruidas por cuerpos diabásicos y nunca en contacto sedimentario con los depósitos de coladas de lava (ver discusión histórica en Alvarado et al., 2009a). No fue sino hasta que las dataciones radiométricas argónargón aportaron las evidencias de que los eventos magmáticos eran en gran parte más jóvenes que las radiolaritas (Sinton et al., 1997; Hauff et al., 2000), por lo que Hauff et al. (2000) propone a modo más regional que los contactos, tanto tectónicos como magmáticos, prevalecían con respecto a los contactos sedimentarios, aspectos previamente observado por otros autores (Gursky \& Gursky, 1989), pero no conceptualizado de modo regional, ni interpretado como peperitas o como intrusiones contemporáneas (i.e., Schwarzer \& Gursky, 2007). Todo lo anterior, más nuevos trabajos de campo, permitieron readecuar los modelos (ver Denyer \& Baumgartner, 2006; Denyer et al., 2006; Alvarado et al., 2009a).

Efectivamente, las radiolaritas se presentan intruidas y en parte afectadas en su estratificación (deformación plástica) por cuerpos hipoabisales diabásicos, presentando decoloración en sus contactos y contactos fríos en los cuerpos ígneos (Gursky \& Gursky, 1989; Denyer \& Baumgartner, 2006), pero hasta el momento no se ha llegado a observar típicas estructuras brechoides, bulbosas o fluidización a nivel de micro-escala entre los componentes ígneos y los sedimentarios. Sin embargo, si se observan megabloques de radiolaritas con intensa deformación plástica, brechiación y pérdida de la estratificación, así como una profusa decoloración y sobre todo, la presencia de una textura de pimienta en las radiolaritas, debido a la intrusión (Fig. 3-A). Excelentes ejemplos se observan al oeste de playa Conchal, por playa Negra (por Paraíso), y las playa Pedregosa y Honda.

Quizás la elevada profundidad a donde ocurrió la intrusión (al menos unos 3 km o más de carga hidrostática), dado que las radiolaritas son distales y los basaltos no vesiculados, aunado a la carga litostática de los sedimentos radiolaríticos (de al menos unos $50 \mathrm{~m}$ ), inhibió la vaporización y explosividad, y por consiguiente la brechiación. Por otro lado, la intrusión al parecer fue lenta dado que los contactos fríos no están muy bien 


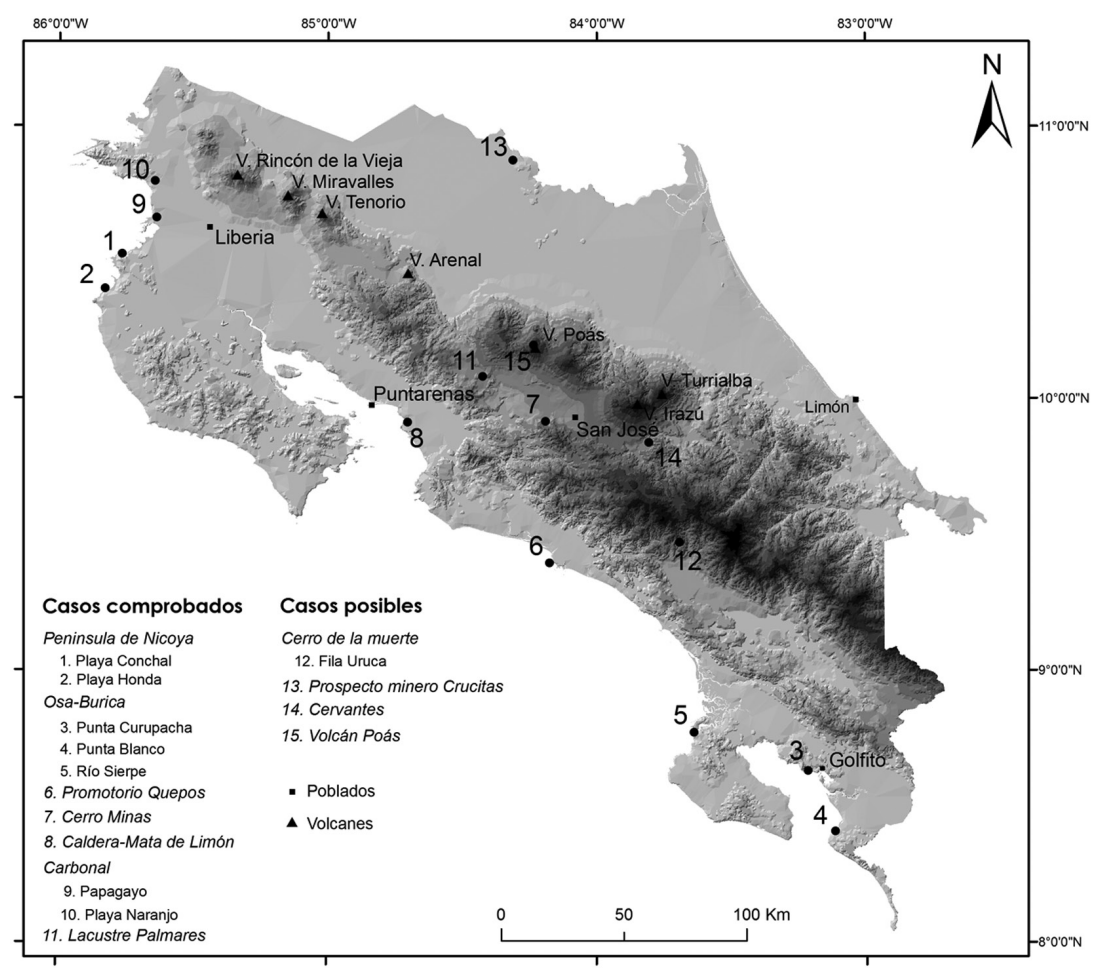

Fig. 2: Mapa de ubicación de los casos de estudio.

definidos, y la bipolaridad geoquímica entre los sedimentos radiolaríticos, (extremadamente ricos en sílice: más de un $95 \% \mathrm{SiO}_{2}$ ) y las lavas basálticas (45-50\% $\mathrm{SiO}_{2}$ ), posiblemente favoreció la inmiscibilidad de ambos tipos de rocas.

Otros ejemplos de posibles peperitas se observan en diversos sectores costeros de la península de Nicoya, en donde los afloramientos debido a la erosión marina, son bastante buenos.

\section{Osa-Burica (Cretácico-Paleoceno)}

En punta Curupacha (aprox. 831' $0.53^{\prime \prime} \mathrm{W} /$ $8^{\circ} 37^{\prime} 56.3^{\prime}$ 'N), en el Golfo Dulce, cerca de Golfito, se observan en los acantilados intrusiones de composición basáltica dentro de las calizas pelágicas del Maastrichtiano-Paleoceno, descritas por Obando (1986) y Di Marco (1994). Aunque ambos autores las habían señalado como indicadores de la coexistencia de un vulcanismo contemporáneo con la sedimentación, no se habían inter- pretado como brechas peperíticas. Efectivamente, poseen un contacto brechoso, de clastos volcánicos angulosos, algunos de formas caprichosas con bordes sinuosos, indicadores de un estado plástico de la lava al momento de la intrusión, en algunos casos contactos fríos y pirometamórficos, pero en otros, la mezcla de los dos componentes es clara y disminuye conforme se aleja de la intrusión (Fig. 5-C). La mezcla ocurre desde escala decimétrica hasta métrica y los clastos desde milimétricos hasta decimétricos, algunos con estructura en rompecabezas.

Otra localidad se ubica por punta Banco, cer-

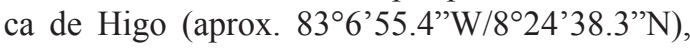
camino a Pavones. Allí se observan cómo las rocas volcánicas intruyen a las calizas silíceas, desarrollando brechas hidroclásticas con estructura en rompecabezas. Las calizas son del Paleoceno Tardío-Eoceno Temprano (Obando, 1986).

En la desembocadura del río Sierpe $\left(83^{\circ} 38^{\prime} 17.5^{\prime \prime} \mathrm{W} / 8^{\circ} 46^{\prime} 24.5^{\prime \prime} \mathrm{N}\right)$ existen rocas de composición basáltica al parecer del Cretácico 

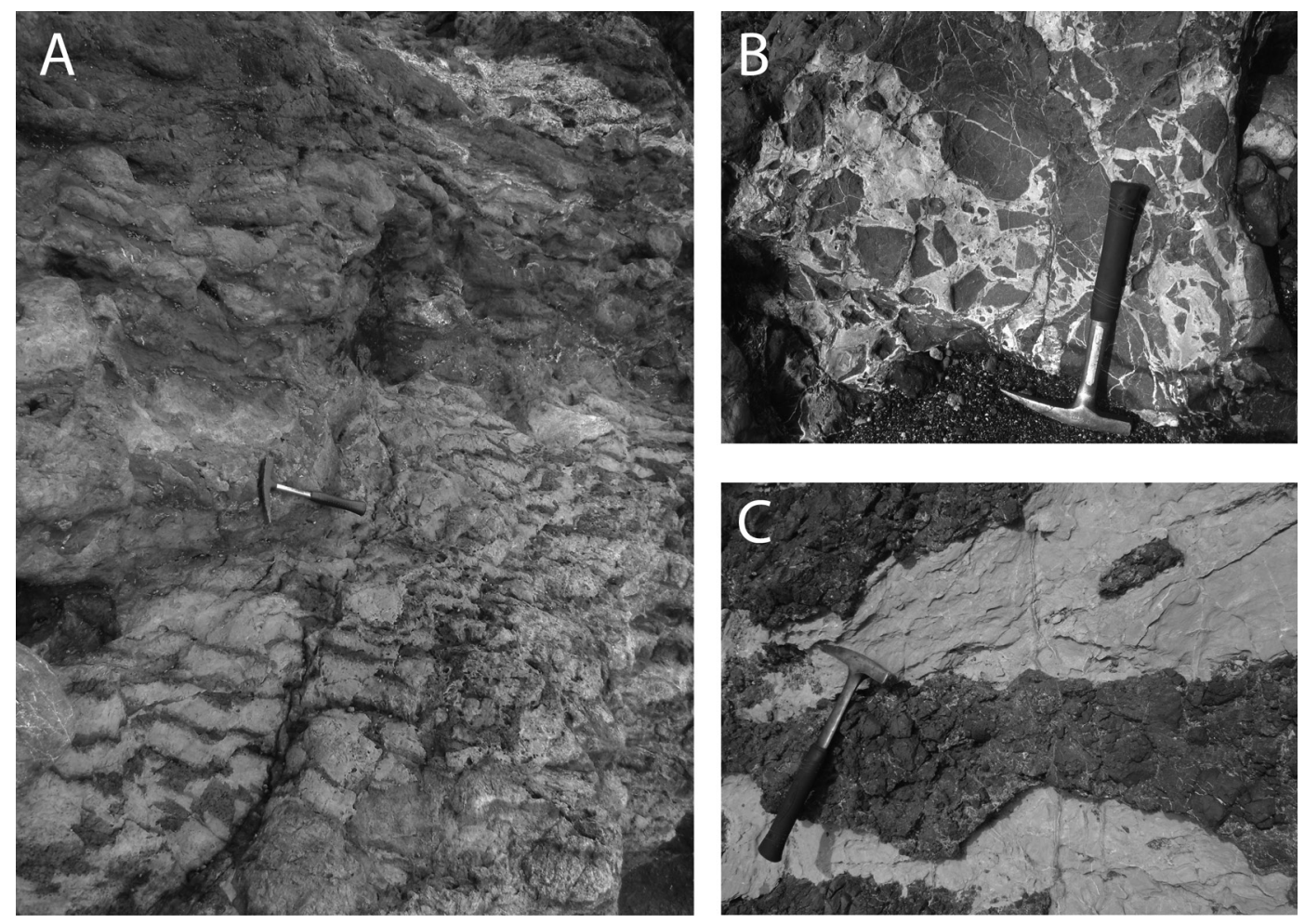

Fig. 3: A) Textura en "sal y pimienta" (megapeperita?) producto de la disrupción de las radiolaritas por efecto de la intrusión básica (extremo sur de playa Conchal, cerro el Encanto). B) Formación de peperitas blocosas por la intrusión de magma basáltico en sedimentos inconsolidados, con textura en rompecabezas indicativa de una fragmentación in situ por hidrofracturación (extremo oeste de playa Espadilla, punta Quepos). C) Delgadas intrusiones de composición basáltica en sedimentos (calizas pelágicas) del Paleoceno, con lentes de arenas hialoclastícas y contactos fríos pero no quemados (punta Quepos).

Superior al Paleoceno (Tournon, 1984; Berrangé et al., 1989). Se trata de flujos de lava en almohadilla basculados, algunos masivos, otros ricos en olivino, intruyendo a radiolaritas, deformándolas y desmembrándolas, con una clara decoloración en los clastos deformados en su borde externo, al contacto con las rocas volcánicas.

\section{Promontorio de Quepos (Paleoceno)}

Schmidt-Effing (1979) interpretó las mezclas de rocas que se observan al oeste de playa Espadilla como resultado de eventos volcánicos. En efecto, observaciones de campo detalladas, evidencian que dichos sedimentos ya existían al momento de que el vulcanismo se desarrollaba, lo que conllevó a interpretarlos como peperitas.
Excelentes ejemplos se observan en punta Quepos y en puerto Escondido. Las principales evidencias son la presencia de bordes fríos en algunos de los clastos basálticos (y menos frecuentemente picríticos) curviplanares a angulares, con la formación de arenas hialoclásticas verdosas (Fig. 4-B), la perturbación de la estratificación de los sedimentos pelágicos (calizas rosadas y blancas del Paleoceno, Fig.3-C), la existencia de estructuras de fluidización y de esquirlas con estructura en mosaico o rompecabezas. Todo esto como evidencias de peperitas blocosas (Fig.3-B), con evidencias claras de hidrofracturación. Sin embargo, también, las lavas en almohadilla suelen tener sedimentos interalmohadilla con hialoclastita entre-mezcladas y con la laminación pelágica claramente disturbada, indicativo que las calizas no obedecen a una lluvia pelágica tranquila pos-vulcanismo e intra-alhomadilla, 

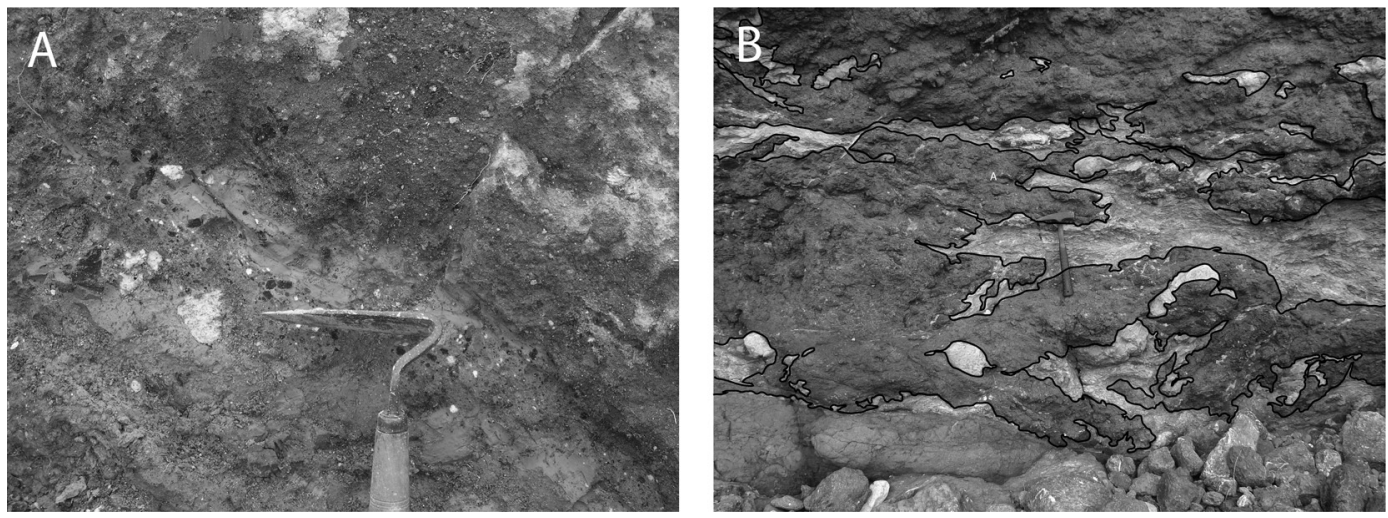

Fig. 4: A) Brecha volcano-sedimentaria entremezclada con una ignimbrita (lapilli pumíticos, escorias, en una matriz de ceniza (cerca de río Grande Palmares). B) Mezcla de dos cuerpos basálticos en sedimentos pelágicos, se aprecia como las calizas rosadas del Paleoceno son envueltas por el material ígneo (punta Quepos).

sino a una intrusión lobular intrasedimentaria, que permitió la disrupción de la laminación pelágica y su mezcla con hialoclastita. La interacción de la lava con los sedimentos húmedos, todavía plásticos, generó lavas en almohadillas, que suelen tener una apariencia brechoide, al grado que se les puede confundir con meras brechas basálticas producto de la erosión de estas lavas. Estos serían ejemplos de peperitas globulares.

\section{Cerro Minas (¿Oligoceno Superior-Mioceno Inf.?)}

Alvarado \& Gamboa (2008) describen los afloramientos de lavas del cerro Minas $\left(84^{\circ} 11^{\prime} 17.6^{\prime \prime} \mathrm{W} / 9^{\circ} 55^{\prime} 8.1^{\prime \prime} \mathrm{N}\right)$ o antiguo Tajo Bretaña, los cuales han sido descritos de una forma somera pese a corresponder con exposiciones excelentes desde hace al menos cuatro décadas. Las descripciones corresponden con dos cuerpos lávicos en el cerro Minas al SW de Santa Ana. Uno de ellos está representada por un roca de composición andesítica porfirítica algo silicificada en la base del tajo como apófisis entre epiclastitas (vulcanoruditas y vulcarenitas y tobas ácidas), estos sedimentos de coloración rojiza a morada se correlacionan con la Formación Pacacua. El otro cuerpo lávico corresponde con una roca de composición andesítica y textura fluidal-bandeada, localmente perlítica devitrificada?, con rampas de progresión "intruidas" por chimeneas de brechas de almohadillas y brechas hialoclásticas. Esta lava presenta en su contacto inferior con la Formación Pacacua, brechas hidroclásticas y peperitas, lo cual sugiere un emplazamiento subvolcánico dentro de los sedimentos. El contacto superior es igualmente con los sedimentos, pero no fue estudiado en detalle (Alvarado \& Gamboa, 2008). Las peperitas suelen ser brechosas al contacto con los sedimentos o globulares, emulando depósitos de flujos de lava en almohadillas (Fig. 5-B).

Estas lavas han tenido diferentes asociaciones litoestratigraficas y edades dependiendo del autor. Sin embargo, las evidencias descritas anteriormente hacen pensar en cuerpos subvolcánicos (criptodomo) que intruyeron a sedimentos inconsolidados y todavía húmedos de la Formación Pacacua (Mioceno Inferior), por lo tanto coetáneos (Alvarado \& Gans, 2012).

\section{Caldera-Mata de Limón (Oligoceno Superior- Mioceno Inferior)}

En un corte reciente de la ampliación de la carretera a Caldera $\left(84^{\circ} 41^{\prime} 29.1^{\prime \prime} \mathrm{W} / 9^{\circ} 55^{\prime} 15.5^{\prime \prime} \mathrm{N}\right)$ en la región del Pacífico Central, se observó un depósito de $5 \mathrm{~m}$ de espesor, compuesta por abundantes fragmentos pumíticos (tamaño de grano medio a grueso) y algunos clastos de lavas, flotando en una matriz vítreo-cristalina, que se interpreta 

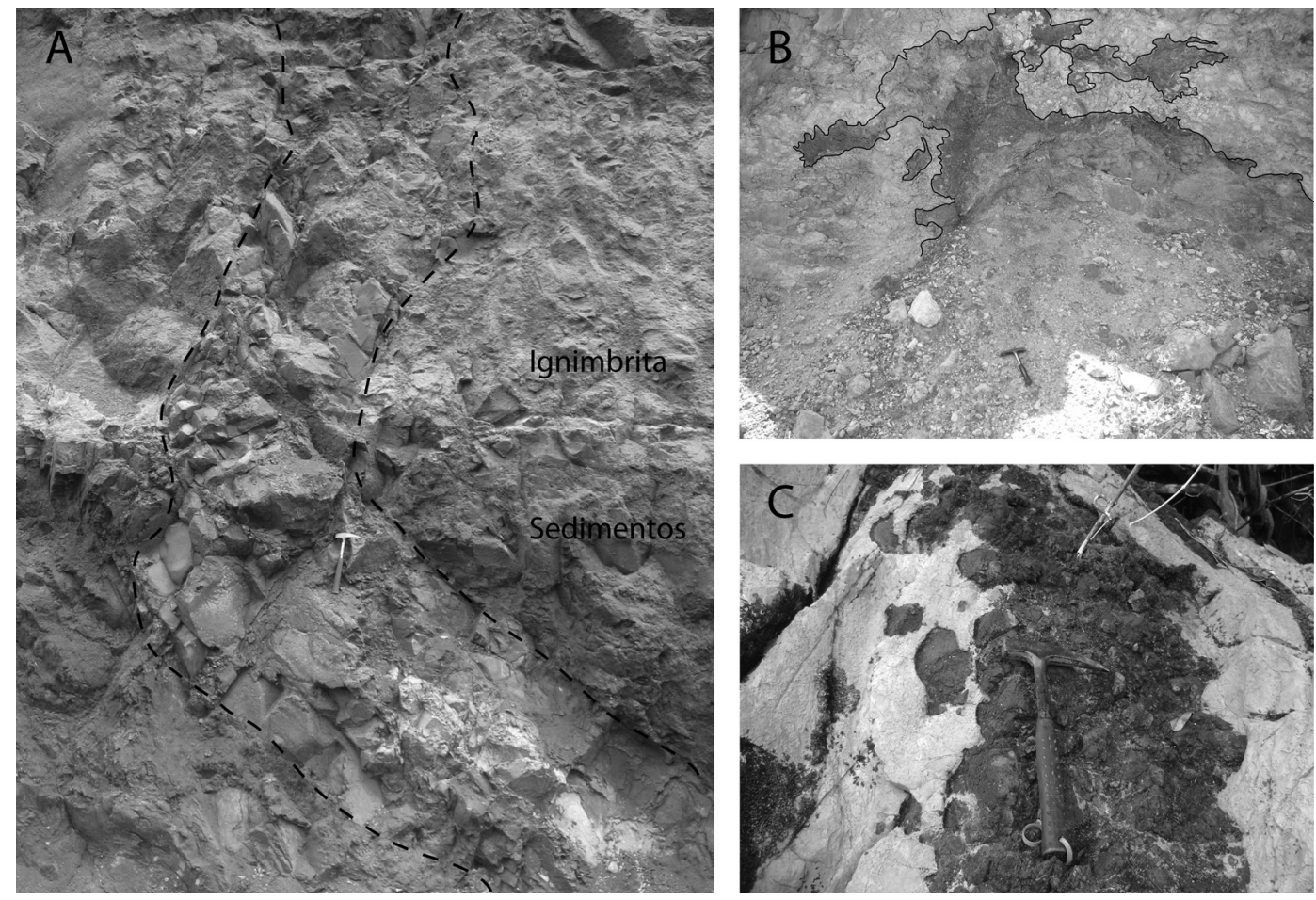

Fig. 5: A) Pipe peperítico, formado por la depositación de una ignimbrita sobre sedimentos fluiviales húmedos del Miembro Mata de Limón. Se observan clastos de los sedimentos rojizos dentro de la ignimbrita verdosa y viceversa (al este de Caldera). B) Sedimentos deformados, brechiados y mezclados con flujos de lava andesíticos (cerro Minas). C) Formación de peperitas con textura mixta por la intrusión de magma basáltico en sedimentos inconsolidados (punta Curupacha, cerca de Golfito).

como un deposito de ignimbrita. La existencia de troncos carbonizados dentro de la ignimbrita soporta la presencia de elevadas temperaturas. Este depósito sobreyace a lutitas y limolitas rojizas, que han sido interpretadas como de origen fluvial, asociado y cartografiado como el Miembro Mata de Limón (Denyer et al., 2003).

$\mathrm{Al}$ contacto entre ambas unidades, se observa como una estructura con forma de dique o chimenea, asciende y se visualiza como una brecha angular mal seleccionada de los fragmentos verdosos ignimbríticos con los sedimentos rojizos, así como un cambio en la decoloración de los sedimentos inferiores de rojizo a crema (Fig. 5-A). Esta estructura se interpreta como una brecha peperítica originada al depositarse la ignimbrita a elevadas temperaturas sobre un lecho de sedimentos todavía saturados en agua, originando una explosión hidroclástica con la consiguiente brechiación, intrusión y mezcla de los sedimentos húmedos dentro del depósitos piroclásticos, y la decoloración y perturbación del paquete de sedimentos rojizos hacia abajo.

Peperitas similares en rocas piroclásticas han sido descritas a nivel mundial, entre ellas en Australia en Mount Read Volcanics al oeste de Tasmania y al noreste de Honshu, en el distrito de Hokuroku, Japón (Gifkins et al., 2002).

\section{Carbonal (Mioceno Superior)}

En los alrededores del complejo turístico Papagayo $\left(85^{\circ} 38^{\prime} 6.5^{\prime \prime} \mathrm{W} / 10^{\circ} 39^{\prime} 53.5^{\prime \prime} \mathrm{N}\right)$ así como cerca de playa Naranjo $\left(85^{\circ} 38,28.2\right.$ " W/ $10 \circ 47,59.8 \% \mathrm{~N}$; $\left.85^{\circ} 37^{\prime} 50.3^{\prime \prime} \mathrm{W} / 10^{\circ} 39^{\prime} 15.5^{\prime \prime} \mathrm{N}\right)$ en el Parque Nacional Santa Rosa, al tope del depósito de flujo de lava dacítico de Carbonal (8 Ma, Alvarado \& Gans, 2012), que constituye en términos regio- 
nales la base de la Formación Bagaces, se observaron mesobrechas angulosas. Poseen contacto puntual a flotante, de espesor variable, algunas con contactos verticales con el depósito, que se presentan mezcladas con sedimentos de origen volcánico amarillentos, sobreyacentes. La mezcla ocurre a escala decimétrica hasta métrica y los clastos varían de tamaños desde milimétricos hasta decimétricos de formas angulares hasta subcurvilíneas e incluso diques clásticos. Se interpretan como brechas hidroclásticas, producto de un contacto hidro-explosivo entre la lava y los sedimentos fluviales sobreyacentes, fluidizando los sedimentos y destruyendo su estructura original. Todo parece indicar que corresponde con una intrusión subvolcánica somera, tipo criptodomo, posiblemente a lo largo de una fisura, bajo sedimentos fluviales volcánicos, aún húmedos.

\section{Lacustre Palmares (Pleistoceno Medio)}

En Palmares, cerca del río Grande, en un corte artificial para construcción a la par de la carretera Interamericana $\left(84^{\circ} 25^{\prime} 18.9^{\prime} \mathrm{W} / 10^{\circ} 4^{\prime} 57.6^{\prime} \mathrm{N}\right)$, se observa como un depósito de ignimbrita con escorias negras, presumiblemente asociada con la Formación Tiribí, que sobreyace al lacustre de Palmares. El contacto es difuso, a través de una brecha sedimentaria tobácea infrayacente, entremezclada con los lapilli pumíticos de la ignimbrita y su matriz de ceniza (Fig. 4-A). No solo se observan clastos sedimentarios angulosos incluidos, sino además, pequeñas intrusiones sedimentarias dentro del depósito de ignimbrita y algunas chimeneas de desgasificación, así como una tosca gradación inversa de los fragmentos de escorias, e incluso de pómez negras mezcladas con los sedimentos. No presenta un contacto quemado bien definido. Todos estos elementos son indicadores de que el depósito de ignimbrita se emplazó al tiempo que el lago aún existía.

\section{Casos posible o potenciales de peperitas}

\section{Cerro de La Muerte (Mioceno Inferior-Medio)}

En el cerro de la Muerte, Quintanilla et al. (2008) reportaron la presencia de posibles peperitas formadas por rocas andesíticas entremezcladas con sedimentos rojizos. Su existencia no sería de extrañar al visualizarse que las edades radiométricas de las rocas ígneas (tanto intrusivas como volcánicas) son contemporáneas con las edades de las rocas sedimentarias (MacMillan et al., 2004). Es por ello, que para la presente investigación, se realizó un reconocimiento geológico más de detalle para situar localidades con peperitas en la región del Cerro de La Muerte. Aunque la localidad específica no se encontró dentro de los taludes cambiantes por inestabilidad y cobertura vegetal, sí se localizó la zona en donde se hallaban los depósitos de flujos de lavas porfiríticos y los sedimentos rojos correlacionados con la Formación Pacacua, en los alrededores de la fila Uruca (aprox. $84^{\circ} 21^{\prime} 31.9^{\prime \prime} \mathrm{W} / 11^{\circ} 26^{\prime} 51.7^{\prime} \mathrm{N}$ ), en donde la carretera Interamericana corta dicha unidad (Alvarado et al., 2009b). También se cuenta con la muestra de mano que evidencia los contactos volcano-sedimentarios.

\section{Crucitas (Mioceno Inferior Tardío-Medio Tardio)}

En el prospecto aurífero de Crucitas, en la zona norte del país cerca de la frontera con Nicaragua, De la Cruz (1994) describe la existencia de peperitas relacionadas con intrusiones magmáticas de composición ácida e intermedia en sedimentos saturados en agua, sugiriendo la existencia de un posible ambiente lagunar intracaldérico. En dichos núcleos, aunque si bien es cierto se observaban sedimentos carbonáceos al contacto con las lavas, estructuras brechoides y 
contactos anómalos, no son claras las relaciones tridimensionales entre las unidades para asignarlas con facilidad el término de peperitas. Estos cuerpos volcánicos y subvolcánicos se asocian al Mioceno Inferior Tardío hasta el Mioceno Medio Tardío (Obando, 1995; Gazel et al., 2005).

\section{Volcán Irazú (Pleistoceno Superior)}

En las investigaciones realizadas por el ICE en el sitio de presa de Cachí (aprox. 8348'16.1'”/ $/ 9^{\circ} 50^{\prime} 26.8^{\prime}$ 'N), Umaña \& Afonso (1969) mencionan que el contacto inferior de la colada de Cervantes (procedente del cono Pasquí, volcán Irazú) con el lacustre infrayacente "está completamente impregnado con materiales plásticos que subieron a las fisuraciones e intersticios de la lava, presionadas por el peso litostático de la colada suprayacente." Ellos no hablan de un contacto quemado en dicho sector y por su descripción, resulta muy sugestivo el pensar de que los sedimentos aún estaban húmedos y que fueron deformados e intruyeron la lava a modo de peperitas.

\section{Volcán Poás (Holoceno)?}

El cráter activo del volcán Poás posee en su interior una laguna intracratérica termomineral hiperácida, de la cual existen espesos (varias decenas de metros) sedimentos tanto lacustrinos antiguos como recientes preservados en sus paredes y bordes de playa. En 1953 se formó un domo colada en el interior de la laguna, llegándose a secar temporalmente la laguna. Hoy día se logran reconocer parte del domo aún no destruido y el flujo de lava en las paredes de la nueva laguna caliente (Soto \& Alvarado, 1989). La existencia de un vulcanismo efusivo y estromboliano en 1953 dentro de un lago volcánico rico en sedimentos finos, hace de este sector un lugar ideal para la formación de peperitas. Desgraciadamente, el nivel actual de la laguna, su peligrosidad (continuas erupciones freáticas) y la alteración hidrotermal, dificultan la detallada observación de la base del flujo.

\section{CONCLUSIONES}

Se presentaron casos en Costa Rica de la inter-relación espacio-temporal entre el magmatismo básico (diabasas, basaltos) con sedimentos plásticos desde pelágicos (radiolaritas y calizas) del Jurásico-Paleoceno, hasta la coexistencia y brechiamiento de basaltos hasta dacitas con sedimentos continentales (sedimentos fluviales hasta lacustres) del Oligoceno Superior y del Mioceno. Las peperitas variaron desde sus tipos brechoides hasta globulares. Un probable caso potencial, histórico, podría corresponder con la erupción del Poás en 1953, en donde la efusión de un domo-colada dentro de la laguna termomineral hiperácida, podría haber desarrollado peperitas en su base.

Relacionados con algunas peperitas se presentan mineralizaciones de oro (p.ej. Crucitas) o posiblemente de cobre tipo malaquita (fila Uruca), o de amatista (cerro Minas), o inclusive alteración hidrotermal hiperácida reciente, como en el caso del domo-colada del Poás. Sin embargo, más estudios son requeridos al respecto.

Se espera que su descripción de campo, criterios de reconocimiento e interpretación, ayuden a reconocer más casos en América Central y su importancia para datar eventos magmáticos y sedimentarios, así como para la prospección de metales preciosos, dada la porosidad congénita de estas brechas y su cercanía con cuerpos dómicos ácidos y sectores con ascensos de fluidos hidrotermales sin y poseruptivos. Muchos más ejemplos de peperitas serán identificadas conforme las investigaciones avancen. 


\section{AGRADECIMIENTOS}

Se aprovecharon algunas giras del ICE y de la Escuela Centroamericana de Geología, para visitar casos conocidos y potenciales junto con el curso de Vulcanología (2009-2010) del I Semestre del IV año de la carrera. Discusiones con James White, fueron muy fructíferas. A Hugo Murcia, Carlos Borrego, Marcelo Arnosio y Teodosio Donaire por sus atinadas observaciones y discusiones al manuscrito y su terminología.

\section{REFERENCIAS}

ALVARADO, G.E., 1984: Aspectos petrológicosgeológicos de los volcanes y unidades lávicas del Cenozoico Superior de Costa Rica.- 183 págs. Univ. Costa Rica, San José [Tesis Lic].

ALVARADO, G.E. \& GAMBOA, D.G., 2008: Las lavas del Cerro Minas (Mioceno Inferior): Un ejemplo de cuerpos subvolcánicos coetáneos con la sedimentación de la Formación Pacacua.- IX Congr. Geol. Amér. Central, San José, Costa Rica: 58.

ALVARADO, G.E. \& GANS, P.B., 2012: Evolución tectono-magmática, metamórfica y metalogenética de Costa Rica, América Central.- Rev. Geol. Amér. Central, 46:7-22.

ALVARADO, G.E., DENYER, P. \& GAZEL, E., 2009a. Endeavor research into evolving paradigms around ophiolites: the case of the oceanic igneous complexes of Costa Rica.- Rev. Geól. Amér. Central, 40: 49-73.

ALVARADO, G.E., BARQUERO, R., TAYLOR, W., MORA, M., PERALDO, G., SALAZAR, G. \& AGUILAR, T., 2009b: Geología de la Hoja San Isidro, Costa Rica.Rev. Geol. Amér. Central, 40: 111-122.
BERRANGÉ, J.P., BRADLEY, D.R. \& SNELLING, N.J., 1989: K/Ar age dating of the ophiolitic Nicoya Complex of the Osa Peninsula, southern Costa Rica.- J. South Amer. Earth Sci., 2(1): 49-59.

BUSBY-SPERA, C.J. \& WHITE, J., 1987: Variation in peperite textures associated with differing host-sediment properties.Bull. Volcanol, 49:765-775.

DE LA CRUZ, R., 1994: Estudio de secciones estratigráficas. Sondajes CP-1 a CP-24, Proyecto Crucitas.- 68 págs. Placer Dome, San José [Inf. Interno].

DENYER, P., AGUILAR, T. \& ALVARADO, G.E., 2003: Geología y estratigrafía de la hoja Barranca, Costa Rica.- Rev. Geol. Amér. Central, 29: 105-125.

DENYER, P. \& BAUMGARTNER, P.O., 2006: Emplacement of Jurassic-Lower Cretaceous radiolarites of the Nicoya Complex (Costa Rica).- Geologica Acta, 4(1-2): 203-218.

DENYER, P., BAUMGARTNER, P.O. \& GAZEL, E., 2006: Characterization and tectonic implications of MesozoicCenozoic oceanic assemblages of Costa Rica and Western Panama.- Geologica Acta, 4 (1-2): 219-235.

DI MARCO, G., 1994: Les terrains accrétés; du sud du Costa Rica: Evolution tectonostratigraphique de la marge occidentale de la plaque Caribe de Costa Rica. -184 págs. Université de Laussane, Mém. Géologie, 20 [Tesis Ph.D.].

GAZEL, E., ALVARADO, G.E., OBANDO, J. \& ALFARO, A., 2005: Geología y evolución magmática del arco de Sarapiquí, Costa Rica.- Rev. Geol. Amér. Central, 32: 13-31. 
GIFKINS, C., McPHIE, J. \& ALLEN, R., 2002: Pumiceous rhyolitic peperite in ancient submarine volcanic successions.- J. Volcanol. Geotherm. Res. 114: 181-203.

GOËR DE HERVE, A., 2000: Peperites from the Limagne trench (Auvergne, French Massif Central: A distinctive facies of phreatomagmatic pyroclastics. History of a semantic drift.- En: LEYRIT, H \& MONTENAT, C. (eds): Volcaniclastic rocks from magmas to sediments.- Gordon \& Breach Sc. Pu, 91-110.

GURSKY, H.G. \& GURSKY, M.M., 1989: Thermal Alteration of Chert in the Ophiolite Basement of Southern Central America.En: HEIN, J.R. \& OBRADOVIĆ, J.A (eds.): Siliceous Deposits of the Tethys and Pacific Regions. Springer, Berlin: 217-233.

HAUFF, F., HOERNLE, K., VAN DEN BOGAARD, P., ALVARADO, G. \& GARBE-SHÖNBERG, D., 2000: Age and geochemistry of basaltic complexes in western Costa Rica: Contributions to the geotectonic evolution of Central America.- Geochemistry, Geophysics, Geosystems, 1(5): 1999GC000020, doi: 10.1029/1999GC000020.

MACMILLAN, I., GANS, P.B. \& ALVARADO, G., 2004: Middle Miocene to present plate tectonic history of the southern Central American Volcanic Arc.- Tectonophysiscs, 392: 325-348.

OBANDO, J., 1986: Sedimentología y tectónica del Cretácico y Paleógeno de la región de Golfito Península de Burica y Península de Osa, provincia de Puntarenas, Costa Rica.- 210 págs. Univ. Costa Rica, San José [Tesis Lic].
OBANDO, J., 1995: Estudio geológico del arco de Sarapiquí: Contribución a las nuevas exploraciones mineras en la región.135 págs. Placer Dome, San José [Inf. Interno].

QUINTANILLA, E.,ALVARADO, G.E., MARÍN, C. \& DURÁN, M., 2008: Estratigrafía de pozos como un aporte al conocimiento de la geología del Cuaternario del valle de El Guarco (Cartago), Costa Rica.- Rev. Geol. Amér. Central, 38: 53-64.

RIVIER, F., 1979: Geología del área norte de los Cerros de Escazú, Cordillera de Talamanca, Costa Rica.- Inf. Sem. IGN, 1972(1): 99132.

SCHMIDT-EFFING, R., 1979: Alter und genese des Nicoya-Komplexes, einer ozeanischen Palaokruste (Objura bis Eozan) im sudlichen Zentral-Amerika.- Geologische Rundschau, 68 (2): 457-494.

SCHMIDT-EFFING, R., 1980: Rasgos fundamentales en la historia del Complejo de Nicoya (América Central Meridional).Brenesia, 18: 231-252.

SCHWARZER, A. \& GURSKY, H.-G., 2007: Ophiolite breccias of the Nicoya Complex, NW Costa Rica - an overview.- Abstracts $20^{\text {th }}$ Colloquium on Latin American Earth Sciences, Kiel, Germany: 11-13.

SKILLING, I.P., WHITE, J.D.L. \& McPHIE, J., 2002: Peperite: a review of magma-sediment mingling.- J. Volcanol. Geotherm. Res., 114 (2002) 1-17.

SINTON, C. W., DUNCAN, R.A. \& DENYER, P., 1997: Nicoya Peninsula, Costa Rica: A single suite of Caribbean oceanic plateau magmas.- J. Geophys. Res., 102: 15507-15520. 
SQUIRE, R., McPHIE, J., 2002: Characteristics and origin of peperite involving coarse-grained host sediment.- J. Volcanol. Geotherm. Res. 114: 45-61.

SOTO, G. \& ALVARADO, G.E., 1989: Procesos volcánicos asociados con el agua subterránea. El caso de los volcanes Arenal y Poás, Costa Rica.- III Congreso Nacional de Recursos Hídricos, San José: 249-261.

TOURNON, J., 1984: Magmatismes du Mesozoique a l' Actuel en Amerique Centrale: L'example de Costa Rica, des
Ophiolites aux Andesites.- 335 págs. Univ. Curie, París [Tesis Ph.D.].

UMAÑA， J.E. \& AFONSO, P.S., 1969: Confección cortina de impermeabilización en lavas cuaternarias de la margen izquierda de la ampliación del proyecto de Cachí.- v +93 págs. Oficina de Geología, Inst. Costarricense de Electricidad, San José [Inf. Interno].

WHITE, J.D.L., McPHIE, J. \& SKILLING, I.P., 2000: Peperite: a useful genetic term.Bull. Volcanol. 62: 65-66. 